\title{
An Integrated Microstructural and Sensory Approach to Describe Apple Texture
}

\author{
P. Allan-Wojtas, ${ }^{1}$ K.A. Sanford, K.B. McRae, and S. Carbyn \\ Agriculture and Agri-Food Canada, Atlantic Food and Horticulture Research Centre, 32 Main Street, \\ Kentville, Nova Scotia, Canada B4N $1 J 5$
}

\begin{abstract}
AdDITIONAL INDEX wORDS. Malus $\times$ sylvestris, microscopy, quality, scanning electron microscopy, SEM, principal component analysis, PCA

AвSTRact. The apple industry worldwide would benefit from an improved and standardized description of fresh-apple textural quality. The description proposed here is unique in that it integrates structural, sensory, and consumer information. To demonstrate its benefits, 24 apple cultivars [Malus $\times$ sylvestris (L.) Mill. var. domestica (Borkh..) Mansf.] were sampled over two harvest seasons and analyzed using microstructural and sensory techniques. Cultivars were selected to cover a range of known sensory textures, and microstructural profiles were compiled in parallel with sensory and instrumental studies. Each cultivar was prepared for conventional scanning electron microscopy (SEM) observation using standard methods. Representative fruit from each cultivar were photographed at three magnifications to visualize fruit architecture, tissue relationships, and size, shape, and arrangement of cells within layers to compile the microstructural profile. A trained sensory panel evaluated the cultivars for crispness, surface coarseness, sponginess, hardness, juiciness, degree of melting, mealiness, and skin toughness while a consumer panel rated liking. This information was compiled into a texture profile. The microstructural and texture profiles were then combined into a cultivar profile for each sample. Cultivar profiles were collected to form a database; subtle similarities and differences among the $\mathbf{2 8}$ market-quality samples were interpreted and noted. With this technique, those structures with similar sensory properties can be identified with some form of microscopy. Clarifying and predicting the parameters that are related to textural quality in new cultivars will streamline the introduction process.
\end{abstract}

Texture is a primary quality attribute of fresh apples (Malus xsylvestris). Fresh apple texture depends on cultivar (Rebouillat and Peleg, 1988), fruit age, and storage conditions. According to Jackman and Stanley (1995) texture is not well defined, adding to the confusion as to what texture truly represents. Although texture has a scientific definition based on mathematical principles, it is generally misunderstood; there is a need for standard and consistent use of terminology.

The texture of food is defined as all the rheological and structural attributes of a product that are perceptible by means of mechanical, tactile, and, where appropriate, visual and auditory receptors (ISO, 1981). The manner in which the tissue and component cells in the skin and flesh of the apple fruit are organized, and how they relate to each other, may be key to understanding how the structure of the fruit affects its textural properties and ultimately the sensory perception(Khan, 1989; Lapsley, 1989).Visual indicators of texture and changes in it can be observed using microscopy and imaging techniques (Kalab et al., 1995). Light microscopy (LM) has been used to measure and describe the size and arrangement of cells in fresh apples, and to relate differences to observed textural differences among cultivars (Reeve, 1953). LM has also been used to characterize textural problems in fresh and processed fruit and vegetables (Reeve, 1970). Scanning electron microscopy (SEM)

Received for publication 24 June 2002. Accepted for publication 3 Dec. 2002. Contribution 2252 from Agriculture and Agri-Food Canada, Atlantic Food and Horticulture Research Centre, Kentville, N.S., Canada. We wish to thank Vivian Agar and Christine Burbidge-Boyd, Agriculture and Agri-Food Canada, Kentville, N.S., for technical assistance; Christiane Deslauriers, Agriculture and Agri-Food Canada, and Danny Davison, Cultivar and Strains Coordinator of the Nova Scotia Tree Fruit Research Foundation (NSTFRF), for samples and helpful discussions; Barry Swanson, Department of Food Science \& Human Nutrition, Washington State University, and Charles Forney and Andrew Jamieson, Agriculture and Agri- Food Canada, Kentville, N.S., for helpful discussions and comments; Agriculture and Agri-Food Canada, Kentville, N.S., and Acadia University, Wolfville, N.S., who provided facilities; the NSTFRF for financial support; Debra Oxby, Agriculture and Agri-Food Canada, Kentville, N.S., for producing Figure 1a; and Christina McRae of EditWorks for structural editing.

${ }^{1}$ Corresponding author; e-mail allanwojtasp@agr.gc.ca. can characterize cellular failure that occurs due to tension, compression, or shear (Bolin and Huxoll, 1987; Diehl et al., 1979). The nature of these cellular failures may be useful for characterizing apple fruit texture. SEM has also been used to characterize both cell area and intercellular spaces, as well as cellular size and shape, to identify differences among apple cultivars (Trakoontivakorn et al., 1988).

Reports on integrating sensory, instrumental, and microstructural test results to give an in- depth description of apples are limited. Szczesniak and Ilker (1988) relate the sensory attribute of juiciness to sample microstructure and instrumental results; sample juiciness detected by the sensory panel depended on cell size, cell wall thickness, tonoplast integrity, and the ratio between cell walls, cytoplasm, and tonoplast. Lapsley (1989) identified relationships between sensory, instrumental, and microstructural descriptions of fresh apple cultivars. Apples that were judged crisp by a sensory panel fractured through cells when tested instrumentally, while those judged mealy fractured between cells, with the cells appearing intact (Khan, 1989; Lapsley, 1989).

More recently, Harker et al. (1997) used a combination of tensile and sensory measurements, combined with cold-stage scanning electron microscopy (Cryo-SEM) of fracture surfaces, to detect differences in tissue strength and juiciness of fruit and root tissues that represented a range of texture types.

An integrated approach is needed to align concepts from the sensory, microstructure, and instrumental fields to understand the relationship between cellular structure and texture (Jackman and Stanley, 1995). The compilation of microstructural profiles is a reasonable starting point to study fresh apple texture. Texture of plant foods is derived from a structural hierarchy and each level depends on the properties in the preceding level and the relative contribution of each component within a level. Therefore, a fundamental understanding of plant structure is essential to understand the events occurring at a cellular and tissue level (Jackman and Stanley, 1995; Khan and Vincent, 1993; Waldron et al., 1997).

Traditionally, relationships between microstructural parameters 
Table 1. Attributes evaluated, procedures and reference material used by trained taste panel.

\begin{tabular}{ll}
\hline Attribute & Procedure \\
Crispness & Bite into the sample with front teeth. Degree to which rupture (crunching sound) is heard as the tissue breaks or shatters.
\end{tabular}

Surface

Place the sample in your mouth and rub tongue over surface of the sample. Assess how coarse or smooth the surface feels.

coarseness

Sponginess

Partially compress the sample between back molar teeth. A spongy sample springs back after being compressed.

Hardness

Place the sample on the back molars and compress evenly. Evaluate the force required to compress the sample.

Juiciness The amount of juice released after compressing for hardness.

Melting Place sample in mouth and count number of chews until sample disappears. A sample that rapidly disappears is extremely melting.

Mealiness $\quad$ Upon chewing the sample breaks into small individual granular or meal-like pieces.

Skin toughness How difficult it is to chew and break down the skin. Assess amount of residual skin left after five chews.

${ }^{2}$ Kraft General Foods Canada Inc., Don Mills, Ont.

yPeek Freans, Nabisco Brands, Ltd., Toronto, Ont.

${ }^{x}$ Chun King Canada Inc., Windsor, Ont.

wCracker Barrel, medium, Kraft General Foods Canada Inc., Don Mills, Ont.

vRegular croutons, Grissonl, Alimenst Culinar Inc., Montreal, Que.

uUnsalted, dry roasted, Planters, Hershey Canada Inc., Etobicoke, Ont.

'Ganong, St. Stephen's, N.B.

sPhiladelphia, Kraft General Foods Canada Inc., Don Mills, Ont.

rAustral, S.P.C. Ltd., Victoria, Australia.

qDaltons Ltd., Toronto, Ont.

pAylmer, Nabisco Brands, Etobicoke, Ont.

and sensory attributes are ordered to reflect the continuum of ratings for a single sensory attribute (e.g., from high to low for the rating of crispness). Fresh apple texture, however, is multidimensional in nature, with each cultivar having a unique combination of sensory attributes. We propose a different approach whereby the relationships among sensory attributes for selected apple cultivars are determined first, and then the micrographs are examined according to the spatial ordering defined by the sensory attributes. The combinations of sensory attributes can then be reflected in the microstructural characteristics of the apples. The objective of this work is to show how this approach can be used to identify microstructural characteristics, and their combinations, that may be useful for describing and quantifying the texture of market-quality apples.

Table 2. Fruit firmness (N) as determined by a Ballauf penetrometer.

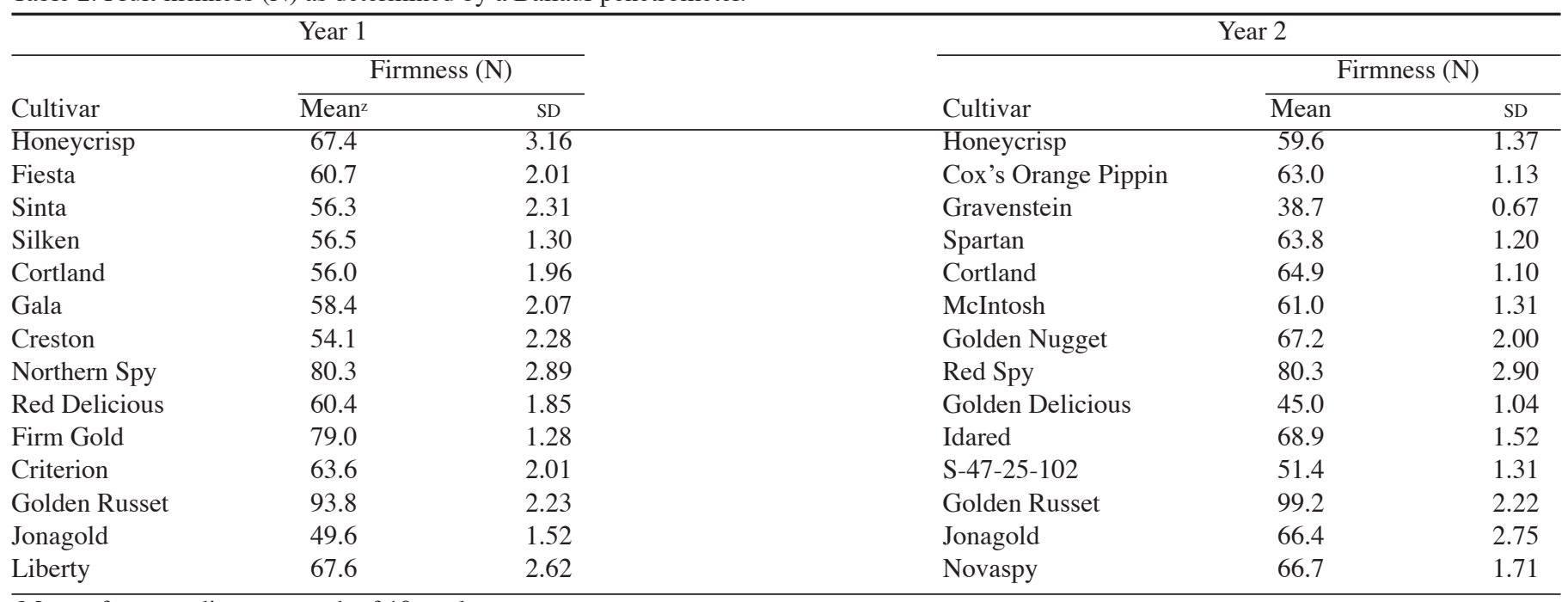

${ }^{\mathrm{z}}$ Mean of two readings per each of 10 apples. 
Reference material

$0 \mathrm{~cm}=$ No crispness (Mini-marshmallow, ${ }^{\mathrm{z}}$ one whole)

$6 \mathrm{~cm}=$ Moderately crisp (Digestive cookie, ${ }^{y} 1.25 \mathrm{~cm}$ square)

$10 \mathrm{~cm}=$ Extremely crisp (Water chestnut, ${ }^{\mathrm{x}}$ one whole)

$0 \mathrm{~cm}=$ No coarseness $\left(\right.$ Cheddar cheese, ${ }^{\mathrm{w}} 1.25 \mathrm{~cm}$ cube $)$

$10 \mathrm{~cm}=$ Extremely coarse (Crouton,,$^{v}$ one whole)

$0 \mathrm{~cm}=$ None $\left(\right.$ Peanut,${ }^{\mathrm{u}}$ one whole $)$

$10 \mathrm{~cm}=$ High sponginess (Marshmallow peanut candy, ${ }^{\mathrm{t}}$ one whole)

$0 \mathrm{~cm}=$ No hardness (Cream cheese, $\mathrm{s} 1.25 \mathrm{~cm}$ cube)

$2 \mathrm{~cm}=$ Just perceptible (Cheddar cheese)

$8 \mathrm{~cm}=$ Very hard (Peanut)

$0 \mathrm{~cm}=$ No juiciness (Mini-marshmallow)

$2 \mathrm{~cm}=$ Just perceptible juiciness (Canned apricot ${ }^{\mathrm{r}}, 1 / 8 \mathrm{th}$ )

$8 \mathrm{~cm}=$ Very juicy (Bottled maraschino cherryq, $1 / 2$ )

$10 \mathrm{~cm}=$ Extremely juicy (Canned peachp, $1.25 \mathrm{~cm}$ piece)

$0 \mathrm{~cm}=$ No melting (Disappears in $18+$ chews)

$10 \mathrm{~cm}=$ Extremely melting (Disappears in 4-6 chews, e.g., watermelon)

$0 \mathrm{~cm}=$ No mealiness (Mini-marshmallow)

$6 \mathrm{~cm}=$ Moderately mealy (crouton)

$8 \mathrm{~cm}=$ Very mealy (digestive cookie)

$0 \mathrm{~cm}=$ none

$10 \mathrm{~cm}=$ high

\section{Materials and Methods}

\section{Apples}

Twenty-eight apple samples were selected to provide a range of market-quality texture attributes. In Year 1, 11 apple cultivars from the Annapolis Valley of Nova Scotia were selected. These included mid-season commercially grown 'Honeycrisp' and 'Cortland' and AFHRC (Atlantic Food and Horticulture Research Centre) grown 'Fiesta' and 'Sinta' and late-season commercially grown 'Northern Spy' and AFHRC grown and harvested 'Firm Gold', 'Starking Red Delicious', 'Liberty', 'Criterion', 'Golden Russet', and 'Nicobel Jonagold'. Commercially grown 'Royal Gala' from the Okanagan Valley in Summerland, B.C. and 'Silken' and 'Creston' from the Pacific Agri-Food Research Centre (PARC) Agriculture and AgriFood Canada (AAFC) apple breeding program were included in the mid-season set. Samples were shipped from British Columbia to Nova Scotia via overnight courier. In Year 2, the cultivars were early to mid-season commercially grown 'Honeycrisp', 'Cox's Orange Pippin', 'Gravenstein', 'Spartan', 'Cortland' and AFHRC grown 'Blackmac McIntosh' and 'Golden Nugget' and mid- to late-season commercially grown cultivars 'Red Spy', 'Golden Delicious', 'Idared', and AFHRC grown election 'S47-25-102', 'Golden Russet', 'Nicobel Jonagold', and 'Novaspy'.

Apples were harvested at commercial maturity for short-term air storage and held at 3 to $4{ }^{\circ} \mathrm{C}$ in common air storage after harvest and before testing, then transferred to room temperature $\left(20\right.$ to $\left.22^{\circ} \mathrm{C}\right)$ $18 \mathrm{~h}$ before testing. Since all cultivars were not ready for harvest at the same time, we stored Year 1 cultivars from 10 to $22 \mathrm{~d}$ before testing and Year 2 cultivars for 9 to $19 \mathrm{~d}$ before testing except for 'Gravenstein' which was held for $24 \mathrm{~d}$. Apples for testing were preselected to meet the Canadian Grade Standards: being without injury by insects and disease, at least $23 / 8$ inches in diameter, and having fruit skin color that matched the parameters for the cultivar. Graded, top-quality fruit within the 100 to 110 pack size were used. For all cultivars harvested at AAFC, maturity for harvest was determined on 10 cut apples using the Cornell Generic StarchIodine Chart for Apples (Cornell, N.Y.) where $1=$ starch present throughout and $9=$ no starch. Optimum harvest for commercially packed cultivars was assessed by the packer's field managers using a combination of techniques based on their experience with each cultivar, and following guidelines and procedures described by Prange et al. (1993) for harvest based on the starch-iodine test, flesh firmness, soluble solids, and predicted harvest date from historical data and days from full bloom.

\section{Sensory analysis}

Trained SENSORY PANEL. Seven screened, trained, and experienced taste panelists quantified eight texture attributes (Table 1) on 10-cm semi-structured scales. Panelists were screened through a series of personal interviews and acuity tests using procedures described by Sanford et al. (1995). The panel developed the descriptive profile and established definitions for all attributes, reference materials, and assessment procedures. During this phase, and the subsequent panelist training phase, a broad range of commercially grown apples and AFHRC apple breeding selections were used to select the descriptive terms and definitions. Panelists who were selected for this experiment received $6 \mathrm{~h}$ of training in the evaluation of apple texture. Before this experiment, experience was gained by participating in the evaluation of apple selections from the AFHRC breeding program for two seasons. For this experiment these trained and experienced panelists received additional three 30-min review sessions each year.

For sensory testing an 11-mm slice including the skin, cut from stem end to blossom end half-way between the blush and non-blush side of the apple, was taken and an 11-mm portion of just the flesh from the center of the slice was used to evaluate flesh texture. The skin was assessed separately. A different apple was given to each panelist and these were subsequently saved for the microstructural analysis described below. Each year, six taste-panel sessions were conducted with the same seven panelists attending three sessions within $4 \mathrm{~d}$ in Year 1 and within $3 \mathrm{~d}$ in Year 2 to test the seven midseason cultivars, and three sessions within $5 \mathrm{~d}$ in Year 1 and within $3 \mathrm{~d}$ in Year 2 to test the seven late-season cultivars. At a session, each panelist evaluated four of the seven cultivars. Cultivars were assigned to panelists using an incomplete block design for seven products and six squares (panel sessions) as described by Wakeling and MacFie (1995). All sensory testing was conducted in an environment-controlled, taste-panel room equipped with individual booths and incandescent lighting. Data were collected with a Compusense 5(CSA, Version 2.4; Compusense Inc., Guelph, Ont.) sensory data collection system.

\section{Firmness}

To provide an indication of the fruit texture at the time of testing, fruit firmness was determined on opposite pared sides of a 10-apple subsample of the fruit on the first day of sensory testing for each set of cultivars, using a penetrometer (Ballauf, Laurel, Md.) with a 11.1-mm-diameter probe. The instrument was calibrated using the procedures described by Bourne (1982). For each cultivar the mean value for firmness $(\mathrm{N})$ and standard deviations were calculated and are reported in Table 2.

\section{Consumer panel}

Consumer testing took place at The Centre for Sensory Research for Food, Acadia University, in Wolfville, N.S. Panelists were recruited through advertisements on campus, e-mail messages, and telephone calls. In Year 1 we recruited 82 females and 44 males; 76 were $<30$ years old, 27 were 30 to 50 years of age, and 23 were $>50$ years of age. Of the test consumers, $71 \%$ reported eating three or more apples a week, while $29 \%$ ate one to two apples a week. In 
a)

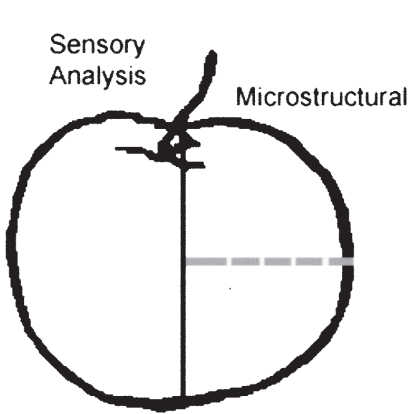

Side View

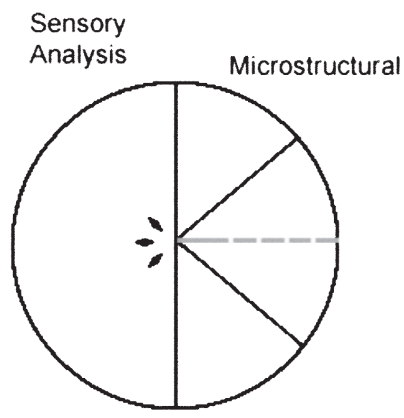

Top View b)

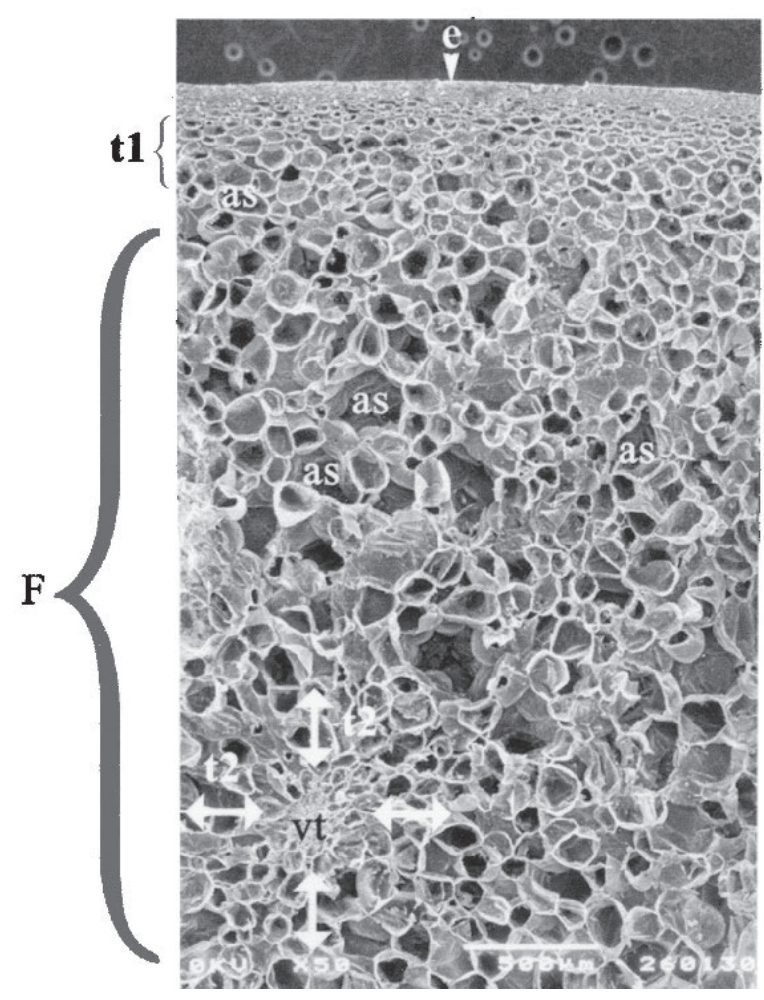

Fig. 1. Sampling for microscopy and definition of terms. (a) Diagram to show the sampling procedure for sensory testing and microstructural testing. (b) SEM micrograph of a typical apple sample ('Golden Russett') showing those structures important for their texture: $\mathrm{e}=$ epidermis; $\mathrm{F}=\mathrm{flesh}$; as = air-space; $\mathrm{t} 1$ $=$ hypodermis, the transition zone between skin and flesh; $\mathrm{vt}=$ vascular tissue $\mathrm{t} 2=$ transition zone between vascular tissue and flesh. Bar $=500 \mu \mathrm{m}$

Year 2 we recruited 89 females and 37 males; 58 participants were $<30$ years old, 34 were 30 to 50 years of age, and 34 were $>50$ years of age. Of these participants, $62 \%$ reported eating three or more apples a week, while $38 \%$ ate one to two apples a week.

Consumer testing was conducted at the same time as the trainedpanel testing and commenced at $0930 \mathrm{HR}$ on the second session day for each set of mid- or late-season trained panels. Each year, each consumer tested four of the seven mid- and four of the seven lateseason cultivars using an incomplete block design as described by Wakeling and MacFie (1995) for seven products and 42 consumers. The 42-consumer design was repeated three times, and cultivars and consumers were randomized following the procedures described by Wakeling and MacFie (1995). Each year a total of 72 responses were collected for each cultivar.

Like trained-panel tests, consumers were presented with a 1$\mathrm{mm}$ slice including the skin, cut from stem end to blossom end half-way between the blush and non-blush side of the apple, with a separate apple tested by each consumer. Each sample was served at room temperature on $15-\mathrm{cm}$ white paper plates each coded with a three-digit random number. Panelists evaluated the samples in taste panel booths equipped with a Compusense 5 (CSA, Version 2.4; Compusense Inc., Guelph, Ont.) sensory data collection system. Each consumer evaluated the four cultivars in the order designated on their scorecard, and rated each sample for liking of texture on a 9 -point hedonic scale ( $1=$ dislike extremely to $9=$ like extremely). Panelists were given room-temperature distilled water to rinse their mouths between samples.

\section{Data analysis and interpretation}

The residual maximum likelihood (REML) directive in Genstat 5 (Genstat 5 Committee, 1993) was used to estimate the cultivar means for each response variate. As a generalization of analysis of variance (ANOVA), REML is better able to analyze unbalanced, multi-strata data. Cultivar information from within and among the incomplete blocks was combined into a single set of means. Prior to conducting the REML analysis, the distribution of the consumer responses for each cultivar was checked and found to be unimodal. Principal component analysis (PCA), operating on the correlation matrix, was used to summarize the trained-panel sensory data and the consumer data, and biplots graphically represented the associations among sensory terms and cultivars. Component scores were multiplied by 7 to scale their size on graphs to be similar to those of the sensory variates. This pictorial display was then compared with micrographs of each cultivar.

\section{Microstructural analysis}

One half of each apple tested by the sensory panelists was used for microstructural evaluation. The microstructural samples were cut from a 2-mm-thick slice at the equator of the apple. This slice

Table 3. Observations and relationships composing a Microstructural Profile.

\begin{tabular}{|c|c|c|}
\hline $\begin{array}{l}\text { Microstructural } \\
\text { information } \\
\text { sought }\end{array}$ & $\begin{array}{l}\text { Viewing } \\
\text { magnification } \\
\text { range } \\
\text { required }\end{array}$ & $\begin{array}{l}\text { Tissue } \\
\text { layers } \\
\text { observed }\end{array}$ \\
\hline Overall tissue architecture & Lowest possible & $\begin{array}{l}\text { Epidermis, parenchyma, vascular tissue (xylem and } \\
\text { phloem) }\end{array}$ \\
\hline Skin, skin/flesh transition zone & Midrange & Epidermis and subepidermal layers; the first layers of \\
\hline Flesh; flesh/vascular tissue transition zone; vascular tissue & Midrange to high-mid & Parenchyma and vascular tissue \\
\hline
\end{tabular}


was further cut with a blade into rectangular samples of dimensions $4 \times 4 \times 2 \mathrm{~mm}$. A series of up to four such samples was taken along the same axis from the skin inward to a depth of $\approx 2.5 \mathrm{~cm}$. (Fig. 1a). These were fixed in $2.5 \%$ glutaraldehyde in $0.05 \mathrm{~m}$ sodium cacodylate buffer, $\mathrm{pH} 7.3$, for at least $48 \mathrm{~h}$ at room temperature. They were then washed for at least $1 \mathrm{~h}$ in $0.05 \mathrm{~m}$ sodium cacodylate buffer, $\mathrm{pH} 7.3$, dehydrated using a graded ethanol series, and critical-point dried from carbon dioxide using a Polaron E3000 critical-point drier (Soquelec Ltd., Montreal, Que.). Dried samples were mounted on aluminum stubs using silver paste. They were coated with gold/palladium using a Hummer VII sputter coater (Anatech Ltd., Alexandria, Va.). Samples were viewed using a JEOL T330A SEM operated at $10 \mathrm{kV}$, and were photographed on either Polaroid Type 55 positive-negative film or Kodak TMAX $35 \mathrm{~mm}$ film. Four to six representative fruit from each cultivar, which had been pre-screened as above, were observed and photographed at three magnifications (low $=50 \times$, intermediate $=350 \times$, high $=1000 \times)$ to view overall skin and flesh architecture and associations of tissue and cellular relationships (Fig. 1b). Of interest were the boundaries and transition zones between fruit tissues, and between like and different cell types within the tissues, because it is at these boundaries that the textural qualities are believed to manifest themselves (Stanley, 1994). These characteristics are outlined in Table 3.

To visualize more clearly differences in cell-to-cell contact in selected cultivars, the photographic negatives produced above were scanned into gray-scale digital files using a Polaroid SprintScan 45 Ultra scanner (Polaroid Canada, Inc., Mississauga, Ont.). The Image Processing Tool Kit (Edition 4.0, Reindeer Graphics, Inc., Asheville, N.C.) was used to convert the gray-scale images into binary images by assigning all gray levels below 125 a value of 0 (white) and all gray levels above 125 a value of 255 (black). These images were manually edited and then inverted to a black on white image to simplify viewing.

\section{Results and Discussion}

\section{Microstructural analysis}

The microstructural hierarchy of samples was observed at the tissue and cellular level. At each level, relationships, as well as descriptions of the component structures, were studied. After surveying the 24 cultivars over a range of pre-determined magnifications, we were able to make several general observations about structural characteristics which were consistent within a cultivar but varied among cultivars.

The epidermis, or skin, is a boundary tissue between the apple and its environment. It is comprised of about two layers of small epidermal cells (Fig. 1b), which range in organization from sheets to columns or groups. Cell shape ranges from rectangular or triangular to thin or flattened. Cell walls range from relatively thick to thin.

The hypodermis or subepidermis (cell layers just below the epidermis, between the epidermis and cortex) was made up of relatively small to medium sized, tightly packed thin- walled cells. The number of layers in this tissue ranged from few to many. It formed a transition zone between the epidermis and the flesh.

The flesh, or cortex, was made up mainly of medium to large parenchyma cells of varying dimensions, wall thicknesses (mostly thin), and orientation. In addition, vascular tissue (strands) ran through the cortex in different amounts (ranging from small to large diameter strands) and arrangements (few to many strands). The vascular tissue was comprised of small cells with very thick (reinforced) cell walls. It was surrounded by a transition zone of cells which separated it from the flesh.

\section{Comparison of sensory and microstructural profiles}

Attempts to describe texture using a single microstructural indicator for each sensory attribute have been unsuccessful (Jackman and Stanley, 1995). As no single attribute of the structure can provide a complete measure of texture, we decided to try identifying combinations of microstructural characteristics that appear to reflect changes in the sensory attributes of apples. To do this a visual map, or biplot (Fig. 2) of the relationships among the apple cultivars was created, based on their sensory attributes. Principal component analysis was used to summarize the sensory data. The eight sensory attributes were reduced to three principal components that explained $79 \%$ of the variation in the texture characteristics of the cultivars, as tested.

Figure 2 shows the relationships among the cultivars and sensory attributes on the first two principal components. Cultivars with similar sensory properties on the first two components tend to be plotted close together.

The first principal component (PC1) had an eigenvalue of 3.6 and explained $40 \%$ of the variation. The component loadings shown in Table 4 contrast the sensory attributes of crispness, hardness, sponginess, surface coarseness, and juiciness with the sensory attributes of melting and mealiness. This dimension primarily describes how the apple sample deforms during compression and subsequent chewing, and contrasts the crisp cultivars with the mealy, melting cultivars. The second dimension (PC2) had an eigenvalue of 2.2 and accounted for $25 \%$ of the variation. It contrasts cultivars with high negative loadings for juiciness and melting to those with high positive loadings for sponginess and hardness. The third principal component (PC3) had an eigenvalue of 1.3 which explained $14 \%$ of the variation in texture. Its positive loadings for skin toughness and mealiness suggest this component represents the mouth-feel of the apple skin.

We found it possible to group together cultivars that appeared to have similar sensory profiles on these dimensions by plotting
Intertissue

relationships

observed

Subepidermal/parenchyma transition zone; air spaces in parenchyma, vascular bundle/parenchyma transition zone

Epidermal layers and subepidermal layers and connections to parenchyma of parenchyma cells

Air spaces; vascular bundle/parenchyma transition zone amount and arrangement of vascular tissue may be related to texture differences
Interpretation

and comments

For orientation and relative amounts, to give general relationships among tissues

Can be important in investigating skin toughness; transitions or lack them can be linked to sensory characteristics

Transitions or lack of them can be linked to sensory characteristics; 


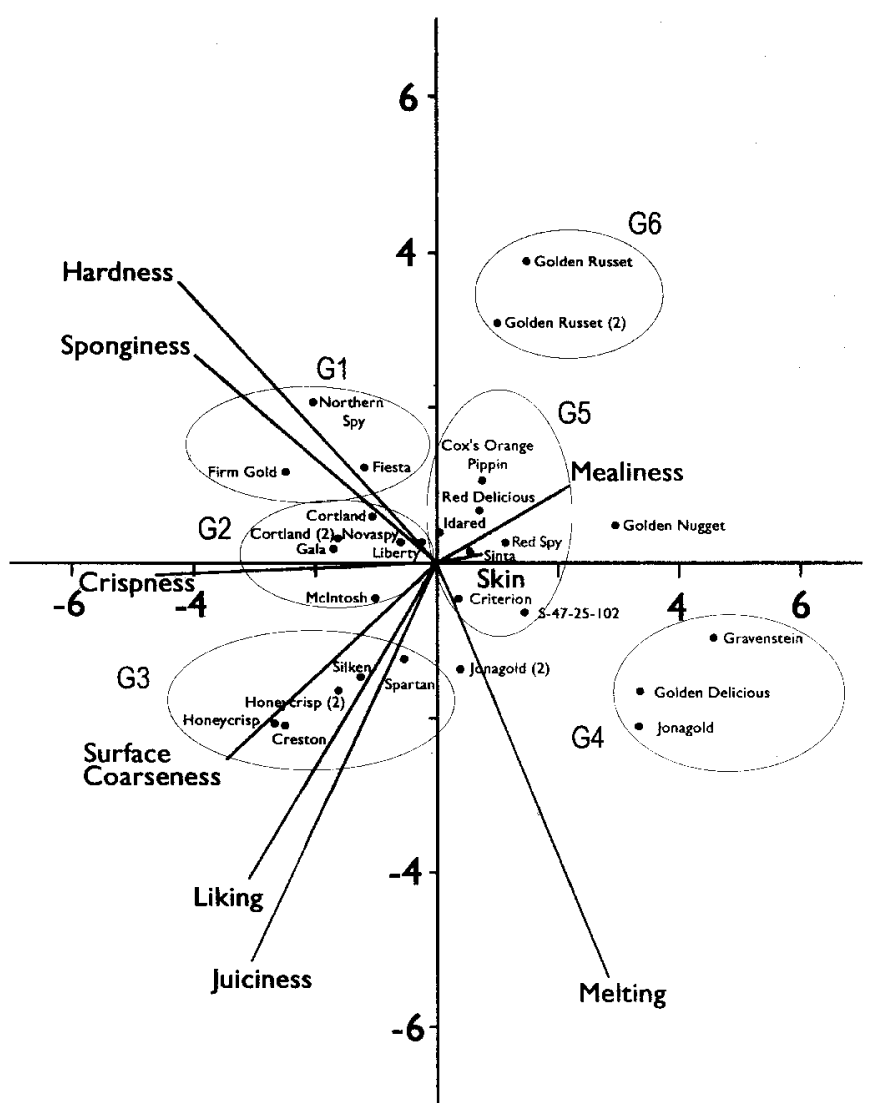

Fig. 2. Biplot of cultivar locations on PC1 (x-axis) and PC2 (y-axis) with the vectors representing the loadings of sensory data along with the principal component scores. Cultivars repeated in Year 2 are indicated by (2).

the component scores for the individual cultivars and graphically representing the sensory attributes. As an example, we present the graphical representation of PC1 and PC2 (Fig. 2). We grouped together cultivars that were close together on PC1 and PC2 and called these groups G1 - G6. Micrographs of cultivars within each of the groups were examined to identify structural characteristics that might define the texture of each group.

The crispest and hardest cultivars (negative scores on PC1) could be separated into three groups, G1 to G3. 'Northern Spy', 'Firm Gold', and 'Fiesta', which comprised the G1 group, were perceived as firm, crisp, and slightly spongy, and moderately juicy and melting. Their flesh was composed of smaller, more denselypacked cells (Fig. 3a) whose cell walls appeared upright and slightly folded over in comparison with the upright and straight cell walls in the G3 cultivars. The different appearances of the cell walls may correspond to the different modes of failure of cell walls described by Jeronimidis (1991): elastic collapse, plastic collapse, and brittle collapse. G1 cultivars appeared to have more vascular tissue than the G3 cultivars and cell size was less uniform.

'Honeycrisp', 'Creston', 'Silken', and 'Spartan' grouped close together and formed the G3 group. They had high negative scores on PC1 and PC2, and while still crisp, were juicy and high in flesh cut-surface coarseness. Their cells cut and fractured cleanly leaving straight-standing cell walls, which were sensed by the panelists when evaluating surface coarseness (Fig. 4a). These juicy cultivars had large, densely-packed cells (Fig. 3b) that appeared to open easily and fracture cleanly. Our observations are in agreement with those of Szczesniak and Ilker (1988) and Harker et al. (1997) who found a)
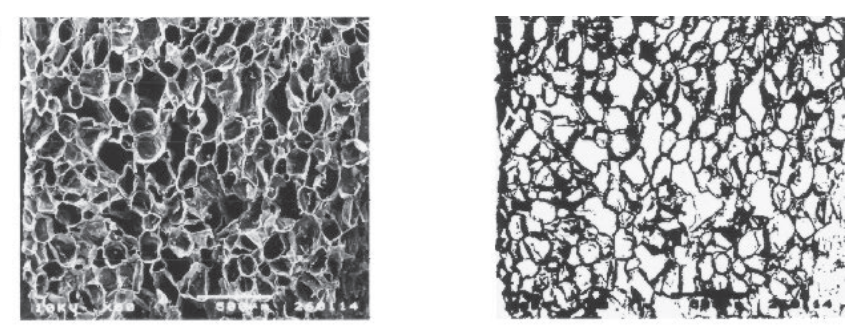

b)
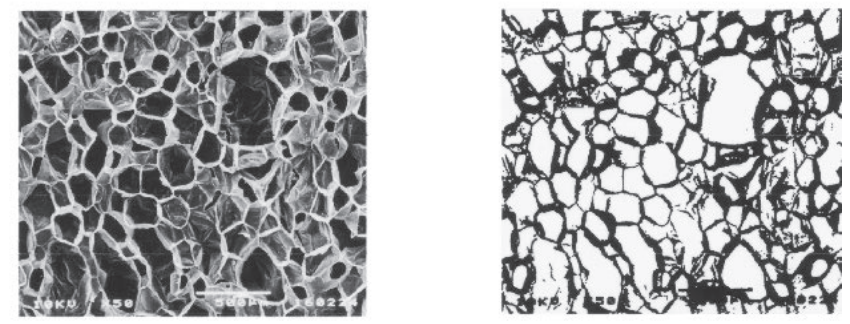

c)
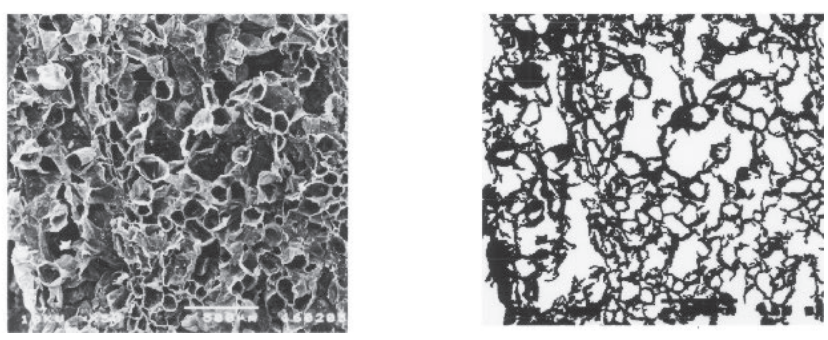

Fig. 3. Range of cell-to-cell contact in flesh. The left column shows representative SEM micrographs while the right column shows their inverted binary images to illustrate cell contact. (a) 'Firmgold', scored as a firm cultivar, is composed of small closely-packed cells. The overall flesh architecture is tight, with few small air-spaces. (b) 'Honeycrisp', scored as a moderately-firm cultivar, is composed of medium and large, closely-packed cells. The overall flesh architecture is tight but more open than 'Firmgold', with medium and large air-spaces. (c) 'Jonagold', scored as a soft cultivar, is composed of small and medium cells arranged in rows and small clusters. The overall flesh architecture is open and loose, with many large air- spaces. Bar $=500 \mu \mathrm{m}$

that juicy samples were composed of large cells with thin, brittle cell walls which fractured easily and cleanly at their equators. Not surprisingly, as shown in Fig. 2, consumer liking of apple texture was closely associated with the attributes in the G3 group. We found that 'Honeycrisp', 'Silken', 'Creston', and 'Spartan' received high hedonic ratings of 7 to 9 by $85 \%, 79 \%, 89 \%$, and $90 \%$, respectively, of the consumers. Previous research by Manola (1990) identified crispness as an important quality attribute, and Daillant-Spinnler et al. (1996), while studying all the sensory properties of selected cultivars, found juiciness, crispness and hardness, along with certain flavor and appearance attributes, to be positively associated with consumer preference. Conversely, the lack of crispness and juiciness, when perceived as mealiness, was found to be a negative quality attribute by Jaeger et al. (1998). In studies using microstructural profiling to improve apple texture, attention should be paid to the microstructural characteristics that define the sensory attributes most closely associated with consumer liking. It must be recognized that consumer liking of apple cultivars is based on more than texture; flavor and appearance characteristics can play important roles in the selection and overall liking of apple cultivars. Some consumers are willing to trade-off texture for certain flavor 
Table 4. Component loadings for sensory attributes and component scores for cultivars.

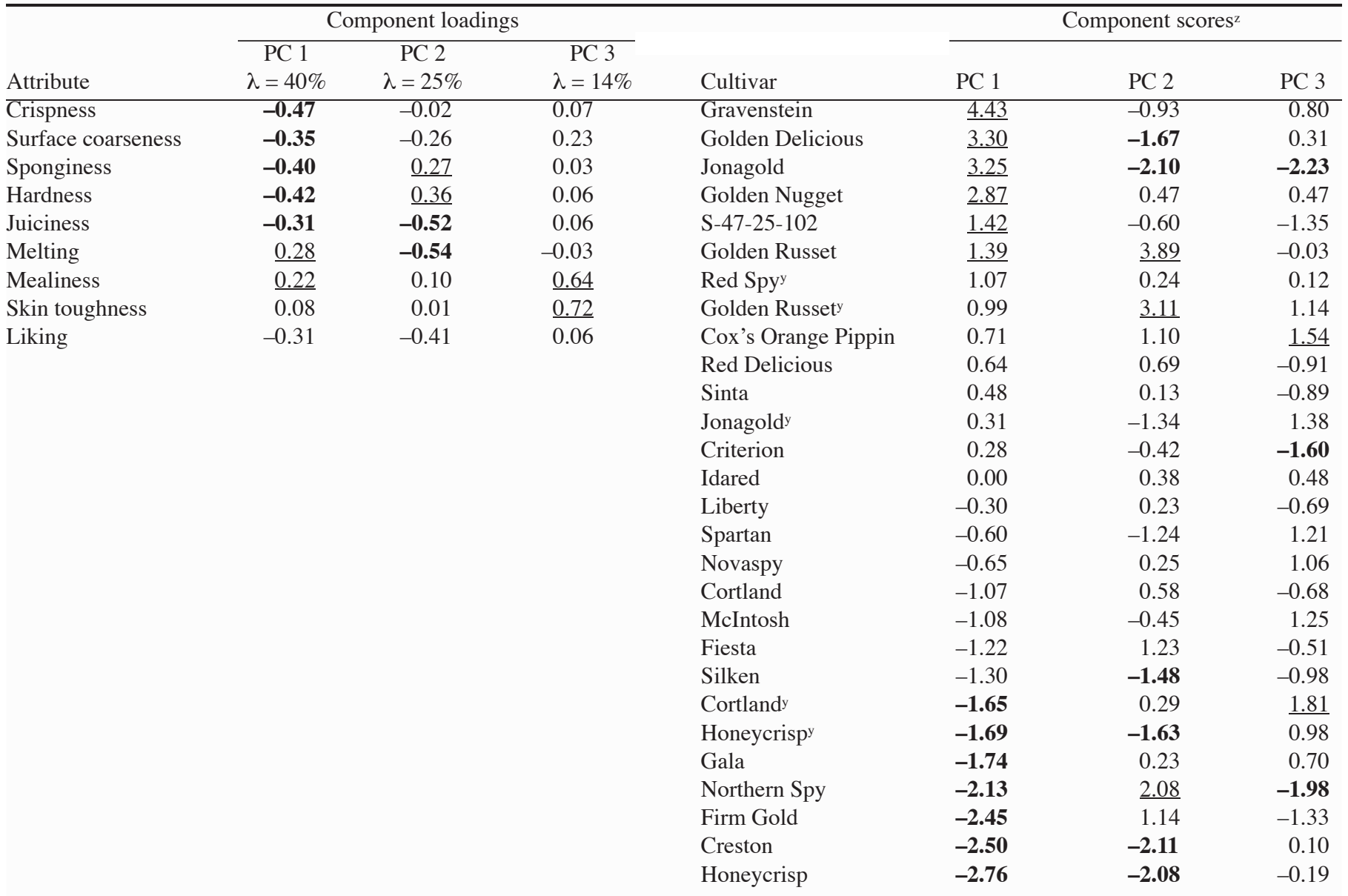

${ }^{2}$ Cultivar scores above the upper LSD (5\%) range, based on scaled variance of 1 unit centered about the origin, are in bold type; those below the lower limit are underlined.

yHarvested in Year 2.

attributes (Daillant-Spinnler et al.,1996).

The sponginess in the G1 cultivars, and in some of the G3 cultivars, may be associated with a gradual increase in cell size from the skin to the flesh over a number of cell layers. This characteristic, also observed in other spongy cultivars like 'Gala', 'Sinta', and 'Golden Russet', might help to explain how a cultivar like 'Honeycrisp', while juicy and high in surface coarseness and crispness, was perceived as slightly spongy. The structure at deeper levels in the flesh (Fig. 4a) shows cells that appear to have fractured cleanly, released juice, and left rigid cell walls. The cell layers between the skin and flesh layers may be more susceptible to compressing without fracturing, and rebounding after compression, thus being perceived as spongy. This shows how the microstructural profile can help to explain what might otherwise have been considered inconsistent panelist ratings.

'Cortland', 'Gala', 'McIntosh', 'Novaspy', and 'Liberty', comprising the G2 group, were structurally intermediate between the 'Honeycrisp' and 'Northern Spy' groups. Cell size was uniform and intermediate between $\mathrm{G} 1$ and G3, and cell walls were less rigid than G3 cultivars. G2 cultivars did not appear to have as much vascular material as $\mathrm{G} 1$ cultivars.

All G1-G3 cultivars were described as 'crisp'. Extremes of texture were not expected in this study as we wanted to describe the subtle, cultivar-specific textural differences of market-quality apples. Our results suggest that the term 'surface-coarseness' might help to differentiate apple cultivars that have similar levels of crispness. Cultivars which scored high for surface coarseness had medium to large cells with cleanly cut or fractured cell walls. The cell walls tended to leave a sharp, clean surface free of buckling or folding, which could be sensed by the tongue (Fig. 4a).

The cultivars in groups G4, G5, and G6 were perceived as less crisp, and in some cases much softer. More air spaces and less cell-to-cell contact were observed in these cultivars, possibly contributing to the perceived slight mealiness or softness. It should be noted that these market- ready apples were still only slightly mealy with the highest sensory mean for mealiness being a 3.2 for 'Cox's Orange Pippin'. It was possible, however, to make textural distinctions among these cultivars. G4 cultivars were softer and juicier than the G6 cultivars, had less cell-to-cell contact (Fig. $3 \mathrm{c}$ ), and broke down more quickly in the mouth. Of particular interest in the G5 group were 'Criterion' and 'S47-25-102' which had similar sensory means scores $(\chi=7.0$ and 7.3 , respectively) for melting as 'Jonagold' in Year 2 (7.5). However, they appeared intermediate to G4 and G6 cultivars in cell size and cell-to-cell contact. The G4 cultivars appeared to have larger and more deeply cut cells, possibly making them juicier and more melting than the G6 cultivars. In addition, the G4 cultivars had the lowest ratings for sponginess. The flesh of these cultivars did not spring back after being chewed and quickly disintegrated in the mouth. The G6 cultivars were more similar to the G1 cultivars with smaller cells, but they had more air spaces and slightly less cell-to-cell contact (data not shown). 
a) Equatorial fracture

I

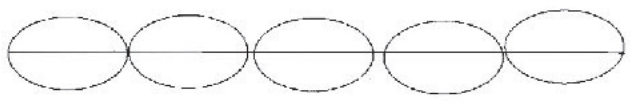

II

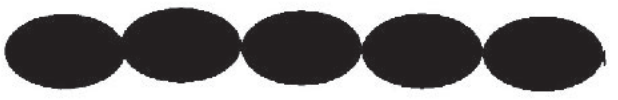

III

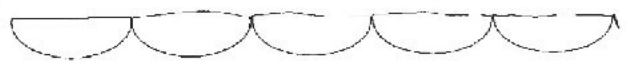

b) Top fracture

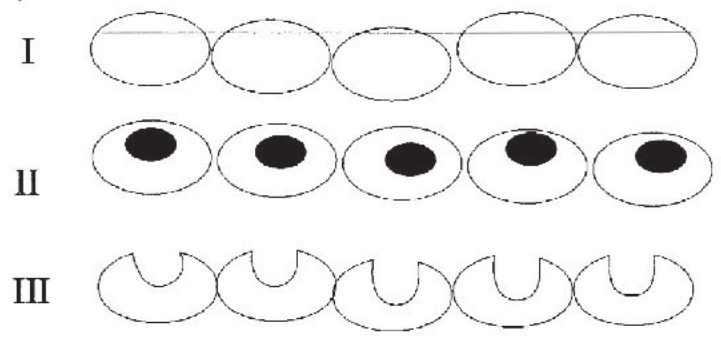

c) Bottom fracture

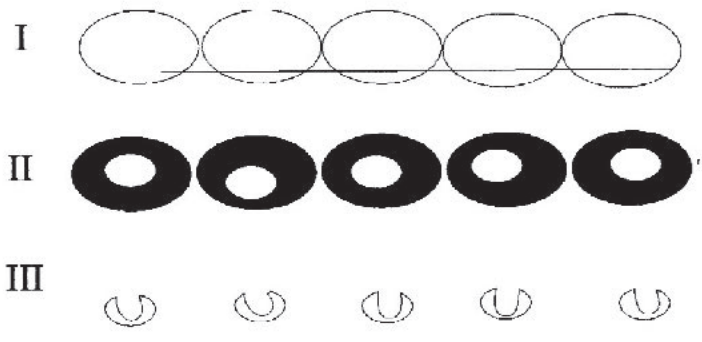

The third principal component explained $14 \%$ of the variation in the texture. This dimension was defined by high positive loadings for skin toughness and mealiness. 'Cox's Orange Pippin', 'Spartan', 'Cortland', and McIntosh had high positive scores in this dimension, while 'Northern Spy', 'Firm Gold', 'Criterion', and the 'Jonagold' apples from Year 1 received high negative scores (Table 4). Although none of the apples tested in our experiment were very mealy, structural properties were observed that were consistent with the microstructural definition of mealiness proposed by Harker and Hallett (1992). They suggest that mealiness was related to the ease with which cells break during chewing. Cell adhesion was low, and individual cells were difficult to burst in the mealy apples. Thus, apples that broke into small clumps of undamaged cells during chewing were perceived as being mealy. Very few undamaged cells were observed on the cut surfaces of the mealy cultivars in our work; the cells appeared to be broken near either end rather than through the middle, and the walls around the hole appeared to be folded over (Fig. $4 \mathrm{~b}$ and c). We found it interesting that even this slight change in structure appeared to affect sensory judgment.

Skin toughness was related to the type and arrangement of the cells in the two layers comprising the skin. 'McIntosh' is known to have a tough skin and received a mean sensory score of 9 for skin toughness. Figure 5a shows the two cell layers of the skin; the outer layer is made up of large, thick-walled, uniformly rectangular cells, which are in close contact, and the inner layer is made up

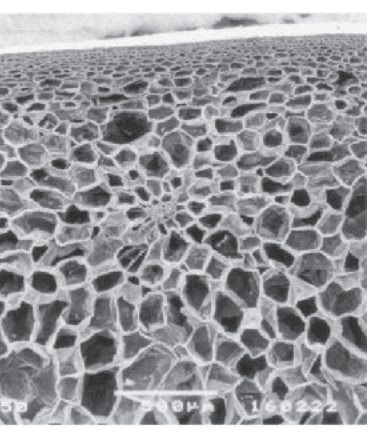

Fig. 4. Relationship of fracture patterns to the sensory term 'surface coarseness'. Diagrams depicting three views of each fracture are proposed for the SEM micrographs shown: $\mathrm{I}=$ side view of whole cells to show the fracture path; II = top view, the view shown in the micrograph, black shows the inside of the cell revealed by the fracture; III = side view to show the

of staggered, thick-walled flattened cells. In contrast, 'Honeycrisp', a new cultivar which has most of the characteristics that consumers associate with high quality, scores moderately high for skin toughness $(\chi=6)$. Its skin did not have two distinct cell layers, but rather up to four, small thinwalled oval cells staggered throughout the area where the two cell layers are usually located (Fig. 5b). Similarly, 'Golden Russet' was scored as having a moderately tough skin $(\chi=7)$. However, the cells of the skin have extremely thick walls that are not organized into layers but clustered into groups of specialized cork cells (Fig. 5c) which extend into the apple to different depths (the structural manifestation of the 'russetting' characteristic). While 'Honeycrisp' and 'Golden Russet' had close to the same sensory scores, structurally the skin was different. To differentiate the differences in skin toughness from a sensory perspective we may need more than one assessment procedure; we focused on evaluating the breakdown after chewing. Additional information may have been provided by rating resistance to puncture by biting into samples with incisors, or possibly by developing a procedure to assess perception of skin thickness.

As indicated in Fig. 2, when tested in both years the cultivars 'Honeycrisp', 'Cortland', and 'Golden Russet' demonstrated less year-to-year differences than 'Jonagold' which placed in grouping G4 in Year 1 but moved closer to G3 in Year 2. Interestingly, there were smaller differences between the initial fruit firmness in Year 1 to 2 for 'Honeycrisp', 'Cortland', and 'Golden Russet' (7, 9, and $5 \mathrm{~N}$ difference, respectively) than for 'Jonagold' $(16 \mathrm{~N})$ (Table 2). In Year 1 the 'Jonagold' sample, as pressure tested, was softer $(50 \mathrm{~N})$ than the Year 2 sample $(66 \mathrm{~N})$. This change was reflected in the placement of the Year 2 'Jonagold' as drawn closer to those groupings associated with the sensory attributes of surface coarseness, crispness, and firmness. It may be worthwhile to evaluate the application of this method to monitor changes in the texture of apples under storage conditions. Harker and Hallett (1992) clearly demonstrate that fruit maturity after extended storage (16 weeks) affected the structural characteristics of 'Braeburn'.

Previous research has focused on the ability of microscopy to define sensory texture based on the differences among largely varying plant foods (Harker et al., 1997; Ilker and Szczesniak, 1990; Szczesniak and Ilker, 1988), and among apples stored under varying conditions (Lapsley, 1989), to demonstrate the relationship between a single sensory attribute and a single microstructural characteristic. This study shows that microscopy can also be used to understand even small differences in the texture in fresh, market-ready apples. 
a)

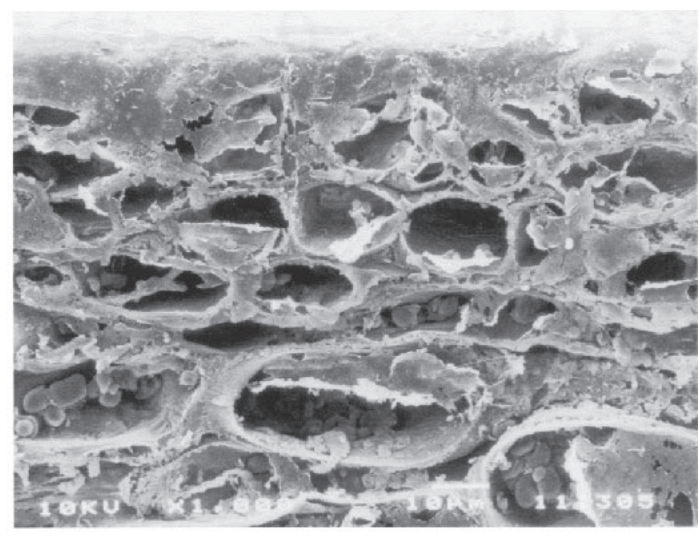

b)

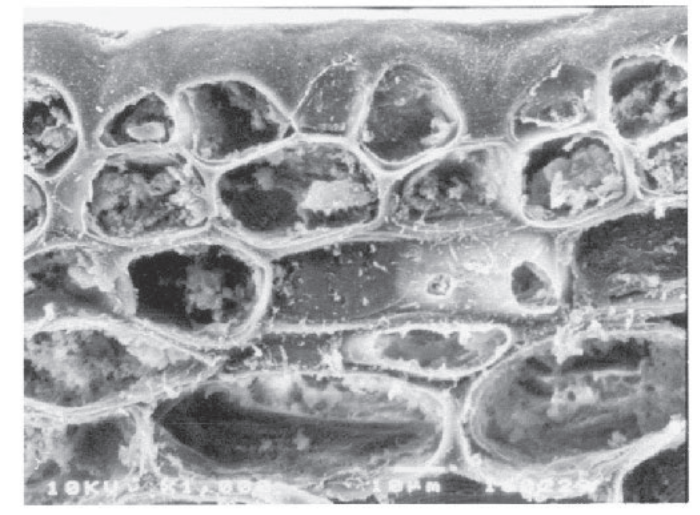

c)

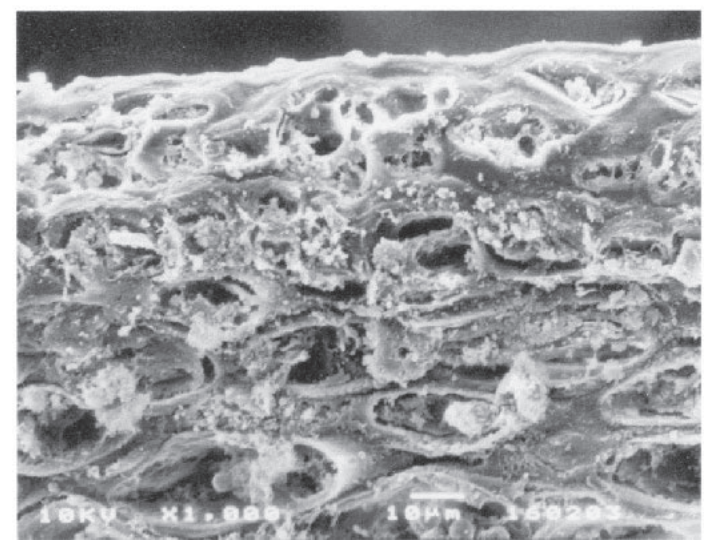

Fig. 5. Skin microstructure is related to the sensory attribute 'skin toughness'. (a) 'McIntosh' scored very high for skin toughness. (b) 'Honeycrisp' scored moderately high for skin toughness. (c) 'Golden Russett' had a moderately tough skin. Bar $=10 \mu \mathrm{m}$

The approach of looking for a combination of microstructural characteristics that is associated with a combination of sensory attributes seems to describe the inherent multi-dimensional nature of apple texture. As previously discussed, many of these apples would be considered crisp, yet a single microstructural characteristic that relates to crispness would not have adequately described the varying textures of these cultivars. Although SEM microscopy is expensive in both material costs and time, rapid advances in digital imaging may soon make this technology more affordable.
In summary, we were able to observe some overall cultivar differences by using microstructural profiling and looking at cultivars at a specific point in time. Cultivars with flesh composed of uniformly large cells that fractured through their centers (Fig. 4a) were perceived as crisp, juicy, and high in surface coarseness - attributes closely associated with consumer liking (Fig. 2). As the cells maintained their rigidity, but became smaller and less uniform in size, they maintained their crispness and firmness but were perceived as less juicy and coarse on the surface. A shift to less cell-to-cell contact and more air spaces was perceived as less crisp with slightly softer flesh (Fig. 3c). If the cells remained large with less cell wall folding, the sample was still perceived as juicy and melting. Unique combinations of the microstructural characteristics of cell size and uniformity, cleanliness of the cell cut/ fracture, and amount and arrangement of vascular tissue appear to differentiate the textures of market-ready apples.

\section{Conclusions}

The integrated approach proposed here can help define textural quality for the fresh apple industry, and can provide a basis for evaluating texture, an important quality characteristic in consumer acceptability of fresh apple cultivars. Subtle textural differences in fresh apples can be quantified, and textural differences better understood, through the identification of microstructural changes.

The compiled pictorial databases can also be used to evaluate whether tissue differences in cultivars accompany traits such as scab resistance, which may carry structural manifestations in other tissues or plant parts. In another application, this unique approach could provide key insights into the measurement and monitoring of quality as affected by pre-harvest and post- harvest treatments such as irrigation, calcium sprays, and shelf-life, which could not have been obtained using any other method.

\section{Literature Cited}

Bolin, H.R. and C.C. Huxsoll. 1987. Scanning electron microscope/image analyzer determination of dimensional postharvest changes in fruit cells. J. Food Sci. 52:1649-1650, 1698.

Bourne, M.C. 1982. Food texture and viscosity: Concept and measurement. Academic Press, New York.

Daillant-Spinnler, B., H.J.H. MacFie, P.K. Beyts, and D. Hedderley. 1996. Relationships between perceived sensory properties and major preference directions of 12 varieties of apples from the southern hemisphere. Food Qual. Preference 7(2):113-126.

Diehl, K.C., D.D. Hamann, and J.K. Whitfield. 1979. Structural failure in selected raw fruits and vegetables. J. Texture Stud. 10:371-400.

Genstat 5 Committee. 1993. Genstat 5 reference manual. Claredon Press, Oxford.

Harker, F.R. and I.C. Hallett. 1992. Physiological changes associated with the development of mealiness of apple fruit during cool storage. HortScience 27:1291-1294.

Harker, F.R., M.G.H. Stec, I.C. Hallett, and C.L. Benett. 1997. Texture of parenchymatous plant tissue: A comparison between tensile and other instrumental and sensory measurements of tissue strength and juiciness. Postharvest Biol. Technol. 11:63-72.

Ilker, R. and A.S. Szczesniak. 1990. Structural and chemical bases for texture of plant foodstuffs. J. Texture Stud. 21:1-36.

ISO. 1981. Sensory analysis vocabulary. Part 4. Intl. Org. Standardization, Geneva, Switzerland.

Jackman, R.L. and D.W. Stanley. 1995. Perspectives in the textural evaluation of plant foods. Trends Food Sci. Technol. 6:187-194.

Jaeger, S.R.,Z.Andani, I.N. Wakeling, and H.J.R. MacFie. 1998. Consumer preferences for fresh and aged apples: a cross-cultural comparison. Food Qual. Preference 9(5):353-366. 
Jeronimidis, G. 1991. Mechanical and fracture properties of cellular and fibrous materials, p. 1-17. In: J.F.V. Vincent and P.J. Lillford (eds.). Feeding and the texture of food. Cambridge Univ. Press, Cambridge, U.K.

Kalab, M., P. Allan-Wojtas, and S.S. Miller. 1995. Microscopy and other imaging techniques in food structure analysis. Trends Food Sci. Technol. 6:177-186.

Khan, A.A. 1988. Mechanical properties of fruit and vegetables. PhD diss. (diss abstr. AADDX-86712.). Univ. Reading, U.K.

Khan, A.A. and J.F.V. Vincent. 1993. Compressive stiffness and fracture properties of apple and potato parenchyma. J. Texture Stud. 24: 423-435.

Lapsley, K.G. 1989. Texture of fresh apples - Evaluation and relationship to structure. PhD diss. Swiss Fed. Inst. Technol., Zurich, Switzerland.

Manola, A.B. 1990. Assessing the importance of apple attributes. N.E. J. Agr. Resour. Econ. 19(2):118-124.

Prange, R.K., M. Meheriuk, E.C. Lougheed, and P.D. Lidster. 1993. Harvest and storage, p. 64-69. In: C.G. Embree (ed.). Producing apples in eastern and central Canada. Agr. Can. Publ. 1899/E, Commun. Branch, Agr. Can., Ottawa, Ont.

Rebouillat, S. and M. Peleg. 1988. Selected physical and mechanical properties of commercial apple cultivars. J. Texture Stud. 19:217-230.
Reeve, R.M. 1953. Histological investigations of texture in apples. II Structure and intercellular spaces. Food Res. 18:604-617.

Reeve, R.M. 1970. Relationships of histological structure to texture of fresh and processed fruits and vegetables. J. Texture Stud. 1:247-284.

Sanford, K.A., C.M. Burbidge-Boyd, M.L.C. Deslauriers, and P. Sarsfield. 1995. Methods for the recruitment and screening of taste panelists for descriptive sensory analyses of apple pies. Tech. Memo. 9502. Food Processing Res., Agr. Can., Res. Sta., Kentville, N.S.

Stanley, D.W. 1994. Understanding the materials used in foods-Food materials science. Food Res. Intl. 27:135-144.

Szczesniak, A.S. and R. Ilker. 1988. The meaning of textural characteristics - Juiciness in plant foodstuffs. J. Texture Stud. 19:61-78.

Trakoontivakorn, G., M.E. Patterson, and B.G. Swanson. 1988. Scanning electron microscopy of cellular structure of Granny Smith and Red Delicious apples. Food Microstruct. 7:205-212.

Wakeling, I.N. and H.J.H. MacFie. 1995. Designing consumer trials balanced for first and higher orders of carry-over effect when only a subset of k samples from t may be tested. Food Qual. Preference 6:299-305.

Waldron, K.W., A.C. Smith, A.J. Parr, A. Ng, and M.L. Parker. 1997. New approaches to understanding and controlling cell separation in relation to fruit and vegetable texture. Trends Food Sci. Technol. 8:213-221. 